\title{
Comparison of breastfeeding self-efficacy and breastfeeding success of obese and normal-weight mothers in the early period
}

\author{
Sinem Ceylan ${ }^{1}$, Sevil Şahin ${ }^{2}$
}

1. Ankara Medipol University, Ankara, Turkey

Email: ceylansinem1@gmail.com

2. Ankara Yildirim Beyazit University, Faculty of Health Sciences, Ankara, Turkey

Email: sevilsahin1@gmail.com

\begin{abstract}
Background: Body mass index (BMI) of overweight and obese women is a risk factor for breast milk secretion.

Aim: This study was conducted in a descriptive and comparative way in order to identify the relation between the breastfeeding success and self-efficacy of obese and non-obese mothers during postnatal period and to make a comparison between the obese and non-obese group.

Methods: The study sample consisted of 113 obese and 111 non-obese mothers that met the study criteria who were hospitalized at the postnatal service of Health Education and Research Hospital in Ankara, September 2014-February 2015.

Result: The mean BMI of obese women prior to the pregnancy was $31.41 \pm 2.4$ while it was $22.25 \pm 2.8$ for the non-obese women. As the BSS scores increase among both the obese and non-obese mothers, the LATCH breastfeeding success score averages increase as well ( $\mathrm{p}<0.05, \mathrm{r}: 0.613)$.

Conclusion: In the light of the data of, to increase the breastfeeding success among obese mothers, it is suggested that the perception of self-efficacy is enhanced, and additional consultation is provided on breastfeeding starting from the antenatal period. The trainings given to mothers by the midwife and nurse are supported with home visits especially in the obese women in the postnatal period in order for them to breastfeeding.
\end{abstract}

Keywords: Breastfeeding success; self-efficacy; maternal obesity.

DOI: https://dx.doi.org/10.4314/ahs.v20i4.60

Cite as: Ceylan S, S Sabin S. Comparison of breastfeeding self-efficacy and breastfeeding success of obese and normal-weight mothers in the early period. Afri Health Sci. 2020;20(4): 2022-31. https:/ / dx.doi.org/ 10.4314/ahs.v20i4.60

\section{Introduction}

Breastfeeding is known to reduce mortality and morbidity rates in infants, to ensure appropriate nutrition, growth and development for infants and to provide economic benefits to family and country with proven superiority to other forms of feeding. Breast milk is the ideal food for the infancy due to several reasons such as varying contents based on infant's needs, features protecting from infections, meeting infant's physiological and psycho-social requirements alone in the first six months and economic advantages ${ }^{1,2}$. In several stud-
Corresponding author:
Sevil Sahin,
Ankara Y1ldırım Beyazıt University,
Faculty of Health Sciences, Ankara, Turkey.
Tel: 00905306003107
Email: sevilsahin1@gmail.com

ies, the mother's educational status, lack of home-care support for the mother and smoking were identified as some of the factors affecting exclusive breastfeeding during the first six months $3,4,5$. Furthermore, there is a negative relationship between maternal obesity and breastfeeding ${ }^{6,7}$.

The prevalence of obesity in pregnancy varies from $1.8 \%$ to $25.3 \%$ according to the $\mathrm{WHO}^{8}$. Studies indicate that the prevalence of obesity among pregnant women is $28.9 \%$, a trend that continues to rise ${ }^{9}$. Obesity is an important risk factor affecting postnatal breastfeeding $^{6}$. There are physiological and psycho-social mechanisms affecting breastfeeding in obese women. Studies showed that maternal obesity (BMI greater than $30 \mathrm{~kg} /$ $\mathrm{m}^{2}$ ) has negative effects on breastfeeding initiation and duration. BMI of overweight and obese women is a risk factor for breast milk secretion. As the prolactin level is lower in breast milk of obese women, milk production decrases. Newborns may have difficulty in sucking due 
to some biological factors such as large breasts, large areolae or inverted nipples in overweight and obese women ${ }^{10}$.

Overweight women have less tendency to initiate and maintain breastfeeding psychologically. Such women are reported to have a negative self-image and low self-confidence as a result of many factors including mental health problems and postnatal depression. Furthermore, overweight women may avoid breastfeeding because of having large breasts from behavioral perspective and lactation may be shorter due to mechanical difficulties in holding and supporting the baby and reduced levels of prolactin in large-breasted women ${ }^{11}$. There are a wide range of factors affecting exclusive breastfeeding at levels lower than desired. The most important one is mothers' lack of information on exclusive breastfeeding, maintenance of breastfeeding, coping with barriers and ideal time to initiate complementary feeding. Accordingly, it is clear that training provided by nurses in the antenatal and postnatal period will support breastfeeding. Nurses can support mothers in deciding to, initiation and maintain of breastfeeding and provide guidance on the ideal time to initiate complementary feeds ${ }^{3}$.

This study was conducted to compare self-efficacy and successful breastfeeding in the early postpartum period among obese women and normal-weight women during hospitalization period.

\section{Method}

\section{Type of Study}

This is a descriptive and comparative study.

\section{Study population}

The study population consisted of 8691 delivered women who presented to Zekai Tahir Burak Hospital from $15^{\text {th }}$ September, 2014 to $15^{\text {th }}$ February, 2015. Antenatal BMI was taken as $\geq 30$ in obese group. Women with a BMI of $<18.5$ were excluded.

\section{Sample of the Study}

The sample size was 105 for each group in the power analysis where alpha was 0.05 , beta was 0.95 and the effect size was 0.05 . Of the women who presented to Zekai Tahir Burak Hospital from 15/09/2014 to $15 / 02 / 2015$, were requested to voluntarily take part in the study; completed a consent form and delivered a baby. One hundred and thirteen obese and 111 normal-weight women were included in the study. Inclusion criteria for the study included having a prenatal BMI of $\geq 30 \mathrm{~kg} / \mathrm{m}^{2}$ in obese group and $<18.5 \mathrm{~kg} / \mathrm{m} 2$ in normal-weight group, having no chronic diseases, having been delivered at least 24 hours ago a full-term and healthy single baby and performing breastfeeding.

\section{Ethical aspects of the study}

Written approvals were obtained from the Ethics Committee of Yildirim Beyazit University to conduct the study. Permission was obtained from the Education Planning Committee of Zekai Tahir Burak Women Health Training and Research Hospital where the study was conducted. The study was supported by the Scientific Research Projects Unit of Yildirim Beyazit University with the project number 1670 . Before the questionnaire was administered, the participants were informed about the purpose of the study and contents of the form and asked to read and sign the consent form for their participation. The participants were informed about the fact that personal data used on the consent form and inhe study would be kept confidential and that they could withdraw from the study any time if they so wished. This would not affect their care.

\section{Data collection instruments}

The Personal Information Form prepared by the investigator in line with the literature ${ }^{3,5,12}$ on demographic characteristics of the mother and infant, Breastfeeding Self-Efficacy Scale and the LATCH Breastfeeding Charting and Documentation Tool ${ }^{13,14}$ were used as data collection instruments.

\section{Personal Information Form}

The forms consists of four sections, namely mother details, pregnancy details, infant details and breastfeeding details. This form questioned mother's details (mother's age, education, working status, family's income level, body mass index before and at the end of pregnancy), pregnancy details (intended pregnancy, number of children, mode of delivery), infant's details (gender, gestational week) and breastfeeding details (breastfeeding experience, having breastfeeding training, breastfeeding initiation time, how long to continue breastfeeding).

\section{Breastfeeding Self-Efficacy Scale-Short Form (Postnatal Version)}

The original 33-item scale was developed by Dennis and Faux to assess maternal self-efficacy levels. In 2003, 14-item short form of the scale was developed. Dennis suggests the use of this short form ${ }^{13}$. As recommended by Bandura, all items are presented positively. This is a 5-point Likert-type scale where 1 indicates "not at all confident" and 5 indicates "always confident". Scores 
are summed to produce a range from 14 to 70 , with higher scores indicating higher levels of breastfeeding self-efficacy. Turkish reliability and validity study of the scale was performed by Tokat and Cronbach's Alpha value was determined as $0.86{ }^{13,14}$. Cronbach's Alpha value of the scale was determined as 0.97 in our study.

\section{LATCH Breastfeeding Charting and Documenta- tion Tool}

The LATCH charting tool contains five key assessment components to which a numerical score of 0,1 , or 2 is assigned for a possible total score of 10 points. Higher scores indicate high breastfeeding success. Turkish validity of the documentation tool was performed by Demirhan in 1997, Koyun in 2001, and Yenal and Okumus in 2003 and it was suggested as a reliable tool. Cronbach's Alpha value of the LATCH Breastfeeding Charting and Documentation Tool was determined to be 0.95 by Yenal and Okumus, 0.94 by Demirhan and 0.96 by Koyun ${ }^{15,16,17}$. Cronbach's Alpha value of the LATCH tool was determined as 0.76 in our study. The LATCH tool was assessed in our study by observing one breastfeeding session of mothers participating in our study.

\section{Conduct of the study}

A pilot study was conducted on 15 women eligible for the study criteria to determine intelligibility of data collection forms ("Personal Information Form", "Breastfeeding Self-Efficacy Scale", "LATCH" Breastfeeding Charting and Documentation Tool") and change of perception during implementation. After the pilot study, questions presenting difficulty in understanding were revised. Data obtained was not included in the analysis.

In this stage, data collection forms were administered by the same investigator face to face to mothers who were eligible for the study criteria and agreed to take part in the study. Data collection period was flexible for each mother who agreed to take part in the study and it was continued to collect data on a daily basis within working hours until the sample size was reached. Interviews were conducted in separate rooms to prevent interaction of mothers.

\section{Data Assessment}

The study consisted of 224 data sets. Data was integrated by transferring to IBM SPSS Statistics 22.0 package program. Descriptive analyses (mean \pm standard deviation) were used for digital data and frequency distribution was given for categorical variables while assessing the study data. The Independent Samples T-Test was used to determine whether there was any difference between two independent groups. One-way Analysis of Variance was used to determine the difference between more than two independent groups. The association between two categorical variables was measured with the Chi-square test at equal interval level and the Pearson's correlation analysis was used to examine the association between variables. The Kolmogorov-Smirnov normality test was used to examine normality for continuous variables. The significance level was accepted as $\mathrm{p}<0.05$ in the study.

\section{Results}


Table 1: Distribution of Individual Characteristics of Obese and Normal-Weight Mothers

\begin{tabular}{|c|c|c|c|c|c|c|c|c|}
\hline \multicolumn{3}{|l|}{$\begin{array}{l}\text { Individual } \\
\text { Characteristics }\end{array}$} & \multicolumn{2}{|c|}{$\begin{array}{c}\text { Obese } \\
(\mathrm{n}=113) \\
X \pm S D\end{array}$} & \multicolumn{2}{|c|}{$\begin{array}{c}\text { Non-obese } \\
(n=111) \\
X \pm S D\end{array}$} & $\mathbf{t}$ & $\mathbf{p}$ \\
\hline \multirow{2}{*}{\multicolumn{3}{|c|}{ Age }} & \multirow{2}{*}{\multicolumn{2}{|c|}{$27.05 \pm 6.1$}} & \multirow{2}{*}{\multicolumn{2}{|c|}{$25.19 \pm 5.1$}} & & \\
\hline & & & & & & & 2.470 & $0.014 *$ \\
\hline \multirow{2}{*}{\multicolumn{3}{|c|}{ BMI of mother before pregnancy*** }} & \multirow{2}{*}{\multicolumn{2}{|c|}{$31.41 \pm 2.4$}} & \multirow{2}{*}{\multicolumn{2}{|c|}{$22.25 \pm 2.8$}} & & \\
\hline & & & & & & & 25.503 & $0.000 * *$ \\
\hline & \multicolumn{2}{|c|}{ Obese } & \multicolumn{2}{|c|}{ Non-obese } & \multicolumn{2}{|c|}{ Total } & \multirow{2}{*}{$\mathbf{X}^{2}$} & \multirow{2}{*}{$\mathbf{p}$} \\
\hline & $\mathbf{n}$ & $\%$ & $\mathbf{n}$ & $\%$ & $\mathbf{n}$ & $\%$ & & \\
\hline \multicolumn{9}{|l|}{ Level of Education } \\
\hline High school & 28 & 24.8 & 20 & 18.0 & 48 & 21.4 & \multirow[t]{2}{*}{1.911} & \multirow[t]{2}{*}{0.385} \\
\hline University & 3 & 2.7 & 5 & 4.5 & 8 & 3.6 & & \\
\hline \multicolumn{9}{|l|}{ Working Status } \\
\hline Yes & 6 & 5.3 & 4 & 3.6 & 10 & 4.5 & \multirow[t]{2}{*}{0.382} & \multirow[t]{2}{*}{0.385} \\
\hline No & 107 & 94.7 & 107 & 96.4 & 214 & 95.5 & & \\
\hline \multicolumn{9}{|l|}{ Profession } \\
\hline Civil Servant/Worker & 4 & 66.7 & 2 & 33.3 & 6 & 50.0 & \multirow{2}{*}{0.333} & \multirow[t]{2}{*}{0.567} \\
\hline $\begin{array}{l}\text { Tradesman/Self- } \\
\text { employed }\end{array}$ & 2 & 33.3 & 4 & 66.7 & 6 & 50.0 & & \\
\hline \multicolumn{9}{|l|}{ Income Status } \\
\hline $\begin{array}{l}\text { Income less than } \\
\text { expenses }\end{array}$ & 14 & 12.5 & 15 & 13.5 & 29 & 13.0 & \multirow{3}{*}{0.985} & \multirow{3}{*}{0.611} \\
\hline $\begin{array}{l}\text { Equal income and } \\
\text { expense }\end{array}$ & 94 & 83.9 & 89 & 80.2 & 183 & 82.1 & & \\
\hline $\begin{array}{l}\text { Income more than } \\
\text { expenses }\end{array}$ & 4 & 3.6 & 7 & 6.3 & 11 & 4.9 & & \\
\hline
\end{tabular}

*:p<0.05 ***BMI: Body Mass Index

$\mathrm{t}$ : Independent Samples T-test, $\mathrm{X}^{2}$ : Chi-square test

In this study, mean age was $27.05 \pm 6.1$ and $25.19 \pm 5.1$ Although not listed in the table, based on the number for obese and non-obese mothers, respectively. Consid- of childbirth, number of pregnancy, mode of delivery ering the preconception body mass index of mothers and regular follow-up during pregnancy for the mothers in the study, preconception BMI was determined as who participated in the study, it was determined that the $31.41 \pm 2.4$ in obese mothers and as $22.25 \pm 2.8$ in nor- both groups were similar with no statistically significant mal-weight mothers. Distribution of individual mater- difference.

nal characteristics is given in Table 1. 
Table 2: Comparison of Breastfeeding Characteristics of Obese and Normal-Weight Mother:

\begin{tabular}{|c|c|c|c|c|c|c|c|c|}
\hline & \multicolumn{2}{|c|}{ Obese } & \multicolumn{2}{|c|}{ Non-obese } & \multirow{2}{*}{ n } & \multirow{2}{*}{$\begin{array}{c}\text { Total } \\
\%\end{array}$} & \multirow[t]{2}{*}{$\mathrm{X} 2$} & \multirow[t]{2}{*}{$\mathbf{p}$} \\
\hline & $\mathrm{n}$ & $\%$ & $\mathrm{n}$ & $\%$ & & & & \\
\hline \multicolumn{9}{|c|}{ Obtaining information on breast milk } \\
\hline Yes & 39 & 34.5 & 30 & 27.0 & 69 & 30.8 & \multirow[t]{2}{*}{1.472} & \multirow[t]{2}{*}{0.225} \\
\hline No & 74 & 65.5 & 81 & 73.0 & 155 & 69.2 & & \\
\hline \multicolumn{9}{|l|}{ Sources of information } \\
\hline Health Institution & 21 & 53.8 & 23 & 76.7 & 44 & 63.8 & \multirow{4}{*}{-} & \multirow{4}{*}{-} \\
\hline Internet & 1 & 2.6 & 0 & 0.0 & 1 & 1.4 & & \\
\hline Pregnancy Class & 2 & 5.1 & 1 & 3.3 & 3 & 4.3 & & \\
\hline Relatives-Acquaintances & 15 & 38.5 & 6 & 20.0 & 31 & 30.4 & & \\
\hline \multicolumn{9}{|c|}{ First breastfeeding after delivery } \\
\hline Within first 1 hour & 112 & 99.1 & 108 & 97.3 & 220 & 98.2 & \multirow[t]{2}{*}{1.055} & \multirow[t]{2}{*}{0.304} \\
\hline After 1 hour & 1 & 0.9 & 3 & 2.7 & 4 & 1.8 & & \\
\hline \multicolumn{9}{|l|}{ Breastfeeding interval } \\
\hline 1-2 hours & 43 & 38.1 & 29 & 26.1 & 72 & 32.1 & & \\
\hline 3-4 hours & 5 & 4.4 & 1 & 0.9 & 6 & 2.7 & & \\
\hline Whenever the infant cries & 65 & 57.5 & 81 & 73.0 & 146 & 65.2 & & \\
\hline \multicolumn{9}{|l|}{ Breastfeeding duration } \\
\hline $5 \mathrm{~min}$. & 3 & 2.7 & 3 & 2.7 & 6 & 2.7 & \multirow{5}{*}{-} & \multirow{5}{*}{-} \\
\hline $6-10 \mathrm{~min}$ & 17 & 15.0 & 10 & 9.0 & 27 & 12.1 & & \\
\hline $11-15 \mathrm{~min}$. & 32 & 28.3 & 25 & 22.5 & 57 & 25.4 & & \\
\hline $16-20 \mathrm{~min}$. & 39 & 34.5 & 43 & 38.7 & 82 & 36.6 & & \\
\hline $20 \min . \uparrow$ & 22 & 19.5 & 30 & 27.0 & 52 & 53.2 & & \\
\hline \multicolumn{9}{|c|}{$\begin{array}{l}\text { Use of supplementary food other than } \\
\text { breast milk }\end{array}$} \\
\hline Yes & 41 & 36.3 & 22 & 19.8 & 63 & 28.1 & \multirow[t]{2}{*}{7.508} & \multirow{2}{*}{$\begin{array}{l}0.006 \\
*\end{array}$} \\
\hline No & 72 & 63.7 & 89 & 80.2 & 161 & 71.9 & & \\
\hline \multicolumn{9}{|l|}{ Liquid/food type given } \\
\hline Water & 1 & 2.4 & 1 & 4.5 & 2 & 3.1 & \multirow[t]{2}{*}{-} & \multirow[t]{2}{*}{-} \\
\hline Formula & 40 & 97.6 & 21 & 95.5 & 61 & 96.9 & & \\
\hline
\end{tabular}

*:p<0.01 t: Independent Samples T-test, $\mathrm{X}^{2}$ : Chi-square test

There was no statistically significant relationship be- that mothers who were trained on breast milk in both tween obesity of mothers in the study, whether they groups received training/information at healthcare inreceived breast milk training and first breastfeeding stitutions mostly. A comparison of breastfeeding chartime after the delivery $(\mathrm{p}>0.05)$. It was determined acteristics of obese and normal-weight mothers is given in Table 2.

Table 3:Examination of relationship between BSES and LATCH breastfeeding success among obese and normal-weight mothers

\begin{tabular}{|c|ccc|}
\hline \multicolumn{4}{|c|}{ LATCH } \\
\hline Obese & \multirow{3}{*}{ BSES } & $\mathrm{r}$ & $\mathbf{0 . 6 1 3}$ \\
Mothers & & $\mathrm{p}$ & $\mathbf{0 . 0 0 0}$ \\
& & $\mathrm{n}$ & 113 \\
\hline Normal-weight & \multirow{2}{*}{ BSES } & $\mathrm{r}$ & $\mathbf{0 . 7 7 4}$ \\
mothers & & $\mathrm{p}$ & $\mathbf{0 . 0 0 0}$ \\
& & $\mathrm{n}$ & 111 \\
\hline
\end{tabular}

*: Breastfeeding Self-Efficacy Scale **: LATCH Breastfeeding Charting and Documentation Tool

***: $p<0.01 \quad r$ : Pearson's correlation analysis 


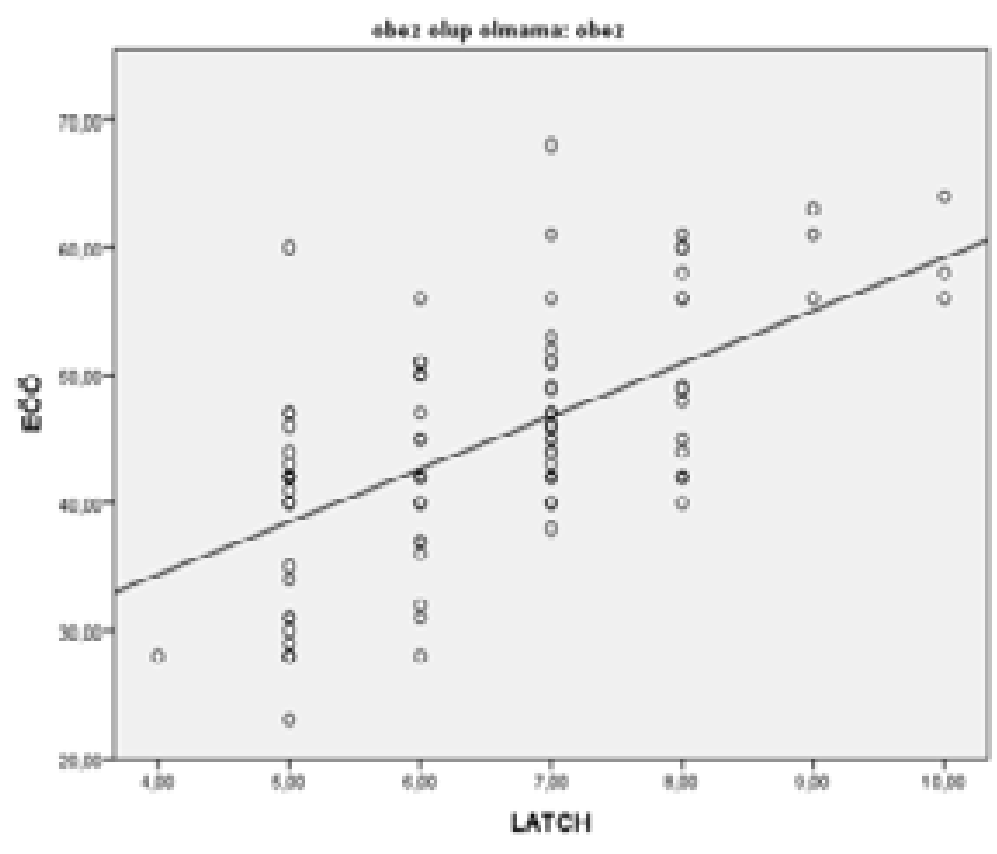

Figure 1. Relationship between postnatal breastfeeding self-efficacy score and LATCH breastfeeding success score of obese mothers.

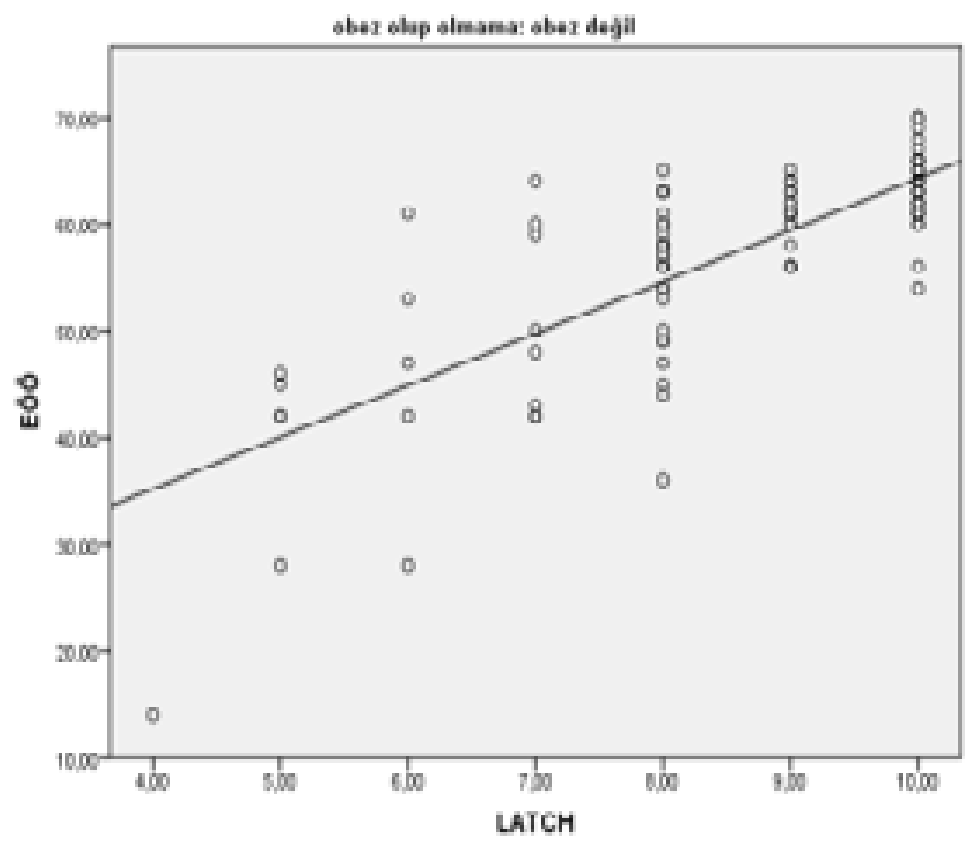

Figure 2. Breastfeeding self-efficacy and LATCH scores of normal-weight mothers in postnatal period 
Upon examination of Table 3, Figure 1 and Figure 2, a strong positive linear relationship was observed between the Breastfeeding Self-efficacy and the LATCH breastfeeding success in obese and normal-weight mothers based on Pearson's correlation analysis $(\mathrm{p}<0.05, \mathrm{r}$ : $0.613, \mathrm{r}: 0.774)$.
In our study, the mean scores of LATCH breastfeeding success increased in line with an increase in the Breastfeeding Self-Efficacy Scale score in both obese and normal-weight mothers $(\mathrm{p}<0.05, \mathrm{r}: 0.613)$. The relationship between BSES and LATCH breastfeeding success of obese and normal-weight mothers is given in Table 3, Figure 1 and 2.

Table 4: Comparison of mean scores obtained by obese and normal-weight mothers from BSES and LATCH scales

\begin{tabular}{|c|c|c|c|c|}
\hline & $\begin{array}{c}\text { Obese }(\mathrm{n}=113) \\
\mathrm{X} \pm \mathrm{SD}\end{array}$ & $\begin{array}{l}\text { Non-obese (n=111) } \\
\quad \mathrm{X} \pm \mathrm{SD}\end{array}$ & $\mathrm{t}$ & \\
\hline BSES & $44.40 \pm 8.771$ & $57.58 \pm 9.167$ & 0.994 & $0.000 *$ \\
\hline LATCH & $6.42 \pm 1.301$ & $8.62 \pm 1.470$ & 1.853 & $0.000^{*}$ \\
\hline
\end{tabular}

*:p<0.001, t: Independent Samples T-Test

The mean BSES score was $44.40 \pm 8.771$ in obese moth- feeding success scores, mean score was determined ers and $57.58 \pm 9.167$ in normal-weight mothers. Accordingly, mean BSES score of normal-weight mothers was found to be significantly higher than that of obese mothers $(\mathrm{p}<0.001)$. As for the LATCH breastas $6.42 \pm 1.301$ in obese mothers and $8.62 \pm 1.470$ in normal-weight mothers. Mean scores obtained by obese and normal-weight mothers from the BSES and LATCH scales are given in Table 4.

Table 5: Comparison of total mean BSES and LATCH scores of obese and normal-weight mothers associated with having training on breast milk and supplementary feeding

\begin{tabular}{|c|c|c|c|c|c|c|c|c|}
\hline & & & $\begin{array}{l}\text { Having } \\
\text { training }\end{array}$ & & $\mathbf{n}$ & $\mathbf{X} \pm \mathrm{SD}$ & $\mathbf{t}$ & $\mathbf{p}$ \\
\hline \multirow{4}{*}{$\begin{array}{c}\text { Obese } \\
\text { mothers }\end{array}$} & \multirow{2}{*}{ BSES } & Yes & & & 39 & $45.69 \pm 8.986$ & \multirow{2}{*}{1.132} & \multirow{2}{*}{0.260} \\
\hline & & No & & & 74 & $43.73 \pm 8.641$ & & \\
\hline & \multirow{2}{*}{ LATCH } & Yes & & & 39 & $6.56 \pm 1.314$ & \multirow{2}{*}{0.825} & \multirow{2}{*}{0.411} \\
\hline & & No & & & 74 & $6.35 \pm 1.297$ & & \\
\hline \multirow{4}{*}{$\begin{array}{l}\text { Normal- } \\
\text { weight } \\
\text { mothers }\end{array}$} & \multirow{2}{*}{ BSES } & Yes & & & 30 & $57.03 \pm 11.016$ & \multirow{2}{*}{-0.385} & \multirow{2}{*}{0.701} \\
\hline & & No & & & 81 & $57.79 \pm 8.451$ & & \\
\hline & \multirow{2}{*}{ LATCH } & Yes & & & 30 & $8.67 \pm 1.516$ & \multirow{2}{*}{0.171} & \multirow{2}{*}{0.864} \\
\hline & & No & & & 80 & $8.61 \pm 1.463$ & & \\
\hline \multirow{4}{*}{$\begin{array}{l}\text { Obese } \\
\text { mothers }\end{array}$} & \multirow{2}{*}{ BSES } & Yes & & & 41 & $40.20 \pm 9.111$ & \multirow[t]{2}{*}{-4.11} & \multirow[t]{2}{*}{$0.000^{*}$} \\
\hline & & No & & & 72 & $46.81 \pm 7.650$ & & \\
\hline & \multirow[b]{2}{*}{ LATCH } & Yes & & & & $5.61 \pm 0.891$ & \multirow[b]{2}{*}{-5.684} & \multirow[b]{2}{*}{$0.000 *$} \\
\hline & & No & & & $\begin{array}{l}41 \\
72\end{array}$ & $6.89 \pm 1.273$ & & \\
\hline \multicolumn{2}{|c|}{$\begin{array}{l}\text { Supplementary } \\
\text { feedingn }\end{array}$} & $\mathbf{X} \pm \mathbf{S D}$ & $\mathbf{t}$ & $\mathbf{p}$ & & & & \\
\hline \multirow{5}{*}{$\begin{array}{c}\text { Obese } \\
\text { mothers }\end{array}$} & \multirow[b]{2}{*}{ BSES } & Yes & 41 & $40.20 \pm 9.111$ & \multirow[t]{2}{*}{-4.117} & \multirow[t]{2}{*}{$0.000^{*}$} & & \\
\hline & & No & 72 & $46.81 \pm 7.650$ & & & & \\
\hline & \multirow{3}{*}{ LATCH } & Yes & & & 41 & $5.61 \pm 0.891$ & \multirow{3}{*}{ - } & \\
\hline & & & & & 72 & $6.89 \pm 1.273$ & & \\
\hline & & No & & & 5.684 & $0.000^{*}$ & & \\
\hline \multirow{4}{*}{$\begin{array}{l}\text { Normal- } \\
\text { weight } \\
\text { mothers }\end{array}$} & \multirow[t]{2}{*}{ BSES } & Yes & 22 & $50.41 \pm 12.105$ & \multirow[t]{2}{*}{-4.435} & \multirow[t]{2}{*}{$0.000^{*}$} & & \\
\hline & & No & 89 & $59.36 \pm 7.350$ & & & & \\
\hline & \multirow{2}{*}{ LATCH } & Yes & 22 & $7.41 \pm 1.532$ & -4.755 & $0.000^{*}$ & & \\
\hline & & No & 89 & $8.93 \pm 1.294$ & & & & \\
\hline
\end{tabular}


The mean scores of both Breastfeeding Self-Efficacy Scale and LATCH breastfeeding success were high in obese women who had information/training on breast milk in our study. Higher supplementary feeding rates in obese and normal-weight mothers were associated with lower mean scores of both Breastfeeding Self-Efficacy Scale and LATCH breastfeeding success. The total mean BSES and LATCH scores of obese and normal-weight mothers associated with having training on breast milk and supplementary feeding are given in Table 5.

\section{Discussion}

Breastfeeding self-efficacy of normal-weight mothers was found to be higher than that of obese mothers in our study (obese mothers: $44.40 \pm 8.771$, normal-weight mothers: 57.58 \pm 9.167$)$. Upon comparison of mean scores of the LATCH breastfeeding success, it was observed that obese mothers had a lower mean score than the non-obese. In Tokat's study where mothers were trained in the prenatal period, breastfeeding self-efficacy score in postnatal week 1 was found to be $56.3 \pm$ 12.6 with a mean score of $7.46 \pm 1.00$ obtained from the LATCH breastfeeding success 8 . Kronborg et al. determined a relationship between maternal obesity and low maternal self-confidence in their study conducted on 1,597 Danish women ${ }^{19}$. Kucukoglu's study on mothers of low-birth-weight infants determined pre-test total mean scores of breastfeeding self-efficacy scale as $41.77 \pm 11.40$ and mean LATCH breastfeeding success as $5.81 \pm 1.72$ among mothers in the control group ${ }^{20}$. Several studies revealed that high breastfeeding self-efficacy level of mothers is very effective on maintenance of breastfeeding ${ }^{21}$. There are some studies suggesting that obese mothers had low determination in meeting their breastfeeding goals and had more limited relatives, friends and social circle breastfeeding their babies ${ }^{22}$. However, no study was found on breastfeeding self-efficacy levels of obese mothers in the literature.

Our study found determined no relationship between having training and mean BSES scores and mean score of LATCH breastfeeding success. Onbasi et al. studied prenatal breastfeeding training on breastfeeding behavior and found out that the use of water, pacifier, formula as well as exclusive breastfeeding rate in the first 6 months was higher in the trained group than the control group $^{23}$. Noel-Weiss et al. established that breastfeeding self-efficacy score after antenatal breastfeeding training was significantly high compared to the control group
24. Chapman et al. found that breastfeeding education affected exclusive breastfeeding uptake up to postpartum 2 weeks in overweight and obese women ${ }^{25}$. Our study revealed no statistically significant relationship between groups having training and no training and found high mean scores of BSES and LATCH breastfeeding success in trained obese mothers. This difference in this study was believed to result from the facts that breastfeeding trainings had conceptual frameworks in examined studies and that mothers who declared to have training underwent only standard, informatory training.

Higher supplementary feeding rates in obese and normal-weight mothers were associated with lower mean scores of both BSES and LATCH breastfeeding success in our study with a statistically significant difference. Baker et al. found that the rate of formula feeding increased with higher maternal BMI ${ }^{26}$. Kronborg et al. found out that obese mothers gave formula at higher rates in their study on Danish women ${ }^{19}$. In their study on 1,151 normal-weight and 580 obese mothers, O'Sullivan et al. established that exclusive breastfeeding rate was $43 \%$ in primiparous normal-weight mothers, but only $29 \%$ in obese mothers who continued breastfeeding 1 month postpartum. Exclusive breastfeeding rate was $57.1 \%$ in primiparous normal-weight mothers and $50.3 \%$ in obese mothers who continued breastfeeding in postpartum 2 months. Similar results were obtained in multiparaous normal-weight and obese mothers with fewer obese mothers who continued exclusive breastfeeding in 1 and 2 months than normal-weight mothers ${ }^{27}$. In their study examining the effect of maternal obesity on breastfeeding success on Hispanic and black women, Kugyelka et al. found no relationship between MSI and formula feeding in two groups; however, a higher rate of supplementary formula feeding was observed in obese Hispanic women ${ }^{28}$. Bartok et al. identified a higher rate of formula feeding in the hospital stay among overweight and obese mothers ${ }^{29}$. Mannion and Mansell conducted a pilot study on breastfeeding self-efficacy and use of galactagogue and found out higher use of formula with decreasing breastfeeding self-efficacy score ${ }^{30}$. Our results are consistent with the literature. It is believed that these low rates result from low number of women who had breastfeeding training.

\section{Limitations of the study}

Data obtained in this study was limited to self-declarations of mothers who delivered at Zekai Tahir Burak Hospital on the study dates. 


\section{Conclusion}

Our study revealed low self-efficacy and breastfeeding success in obese mothers compared to normal-weight mothers. A significant relationship was found between breastfeeding self-efficacy and breastfeeding success in both obese and normal-weight mothers. In the light of the data, and in order to increase the breastfeeding success among obese mothers, it is suggested that the perception of self-efficacy is enhanced, and additional consultation is provided and breastfeeding starting from the antenatal period. The training given to mothers by the midwife and nurse should be re-inforced with home visits especially in the obese women in the postnatal period in order for them to breastfeed.

\section{Acknowledgments}

The authors would like to thank the pregnant women who participated in the study.

\section{Authors' Note}

- This study was presented as an Oral Presentation at the 1st International Congress on Women's Health and Education, Kocaeli-Turkey, 14-15 April 2016.

- This study was produced from the Master's thesis. Ankara Yıldırım Beyazıt University, Institute of Health Sciences, Master Thesis, 2016.

\section{Declaration of conflicting interests}

The authors declared no potential conflicts of interest with respect to the research, authorship, and/or publication of this article.

\section{References}

1. Yurdakok K. Feeding with Breast Milk, Erdem G (Editor). Ankara, Alp Ofset, 2004: 166-174.

2. Samur G, Breast Milk. Ankara, SaglikBakanligiYayinlari, 2008: 9-10.

3. Akyuz A, Kaya T, Senel N. Determination of Breastfeeding Behaviors of Mothers and Influencing Factors, KorHek, 2007,6 (5): 331-335.

4. Kondolot M, Yalcin SS, Yurdakok K. The factors that affect exclusive breastfeeding status, Journal of Pediatrics, 2009, 51: 122-127.

5. Bolat F, Uslu S, Bolat G, Bulbul A, Arslan S. Factors Affecting Breast Feeding in the First Six Months of Life, J Child, 2011, DOI: 10.5222/ j.child.2011.005.

6. Erkekoglu P, Giray B, Sahin G. The toxicological evaluation of the usage of antiobesitic drugs in pregnancy and lactation, Acta Medica (formerly Hacettepe Medical Journal, 2008, 39(3): 121-133.
7. Apay SE, Kilic M, Pasinlioglu T. Labor and Postpartum Period in Obese Pregnant. TAF Preventive Medicine Bulletin, 2010, 9(2): 151-156.

8. Arslan CG. Determination of breastfeeding self-efficacy and related factors in postpartum period. Graduate School of Health Sciences, Nursing Department, Konya, Selcuk University, 2011.

9. Lepe M, Bacardí-Gascón M, Castañeda-González LM, PérezMorales ME, Jiménez-Cruz A. Effect of maternal obesity on lactation: systematic review. Nutricion Hospitalaria, 2011, DOI:10.3305/ nh.2011.26.6.5388.

10. Anstey EH, Jevitt C. Maternal obesity and breastfeeding, Clinical Lactation. 2011, 2(3): 11-16.

11. McGuire W, Dyson L, Renfrew M. Maternal obesity: consequences for children, challenges for clinicians and carers. Seminars in Fetal and Neonatal Medicine, DOI: $10.1016 /$ j.siny.2009.09.005.

12. Institute of Population Studies. Population and Health Research for Turkey 2008. http://www.hips. hacettepe.edu.tr/TNSA2008-AnaRapor.pdf. April 02, 2015

13. Dennis CL. Breastfeeding initiation and duration: a 1990-2000 literature review. Journal Of Obstetrics Gynecologic And Neonatal Nursing, 2002, 31: 12-32.

14. Tokat MA, Okumus H. How to Improve Nursing Practices - Based on Theory and Model for Successful Breastfeeding. Turkish Journal of Research \& Development in Nursing, 2008, 3: 51-58.

15. Demirhan F. Assessment of breastfeeding in the province of Sakarya. Institute of Health Sciences, Department of Pediatrics Nursing, Postgraduate Thesis, Istanbul, Marmara University, 1997.

16. Koyun K. Usage of LATCH breastfeeding assessment tool and the effects on the breastfeeding success. Institute of Health Sciences Gynecology Nursing Department Postgraduate Thesis, Izmir, DokuzEylul University, 2001.

17. Yenal K, Okumus H. Reliability of LATCH breastfeeding assessment tool. Turkish Journal of Research \& Development in Nursing, 2003, 1: 38-44.

18. Tokat MA. The effect of antenatal education on mothers breastfeeding self -efficacy and breastfeeding success. Institute of Health Sciences Gynecology Nursing Department Doctoral Thesis, Izmir, DokuzEylul University, 2009.

19. Kronborg H, Vaeth M, Rasmussen KM. Obesity and early cessation of breastfeeding in Denmark. European Journal of Public Health., 2013, 23(2):316-22.

20. Kucukoglu S. Effect of natural feeding training provided to mothers of low-birth-weight infants on 
breastfeeding self-efficacy level, breastfeeding success and infant growth. Institute of Health Sciences, Department of Pediatrics Nursing, Doctoral Thesis, Erzurum, Ataturk University, 2011.

21. Forster D, McLachlan H, Lumley J. Factors associated with breastfeeding at six months postpartum in a group of Australian women. International Breastfeeding Journal, 2006, 1(18): 1-18.

22. Hauff LE,Leonard SA,Rasmussen KM. Associations of maternal obesity and psychosocial factors with breastfeeding intention, initiation, and duration. The American Journal of Clinical Nutrition, 2014, 99(3): 524-34. DOI: 10.3945/ajen. 113.071191.

23. Onbasi S, Duran R, Aladag CN, Vatansever U, Acunas B, Sut N. The effect of prenatal breast-milk and breast-feeding training given to expectant mothers on the behaviour of breast-feeding. Turkish Archives of Pediatric, 2011, DOI: 10.4274/tpa.46.13.

24. Noel-Weiss J, Rupp A, Cragg B, Bassett V, Woodend K. Randomized Controlled Trial to Determine Effects of Prenatal Breastfeeding Workshop on Maternal Breastfeeding Self-Efficacy and Breastfeeding Duration. Journal of Obstetric, Gynecologice Neonatal Nursing, 2006, 35 (5): $616-624$.
25. Chapman DJ, Morel K, Bermúdez-Millán A, Young S, Damio G, Pérez- Escamilla R. Breastfeeding education and support trial for overweight and obese women: a randomized trial. Pediatrics. 2013, 131(1):162170.

26. Baker LJ, MichaelsenFK, Rasmussen MK, Thorkild IAS. The American Journal of Clinical Nutrition, 2004, 80: 1579-1588.

27. O'Sullivan EJ, Perrine CG, Rasmussen KM. EarlyBreastfeedingProblems Mediate the Negative Association betweenMaternalObesityand ExclusiveBreastfeedingat 1 and 2 Months Postpartum. The Journal of Nutrition, 2015, 145(10): 2369-78. DOI: 10.3945.

28. Kugyelka JG, Rasmussen KM, Frongillo EA. Maternal obesity is negatively associated with breastfeeding success among hispanic but not black women. Journal of Nutrition, 2014,134: 1746-1753.

29. Bartok CJ, Schaefer EW, BeilerJS, Paul IM. Role of Body Mass Index and Gestational Weight Gain in Breastfeeding Outcomes. Breastfeeding Medicine,2011, DOI: 10.1089/ bfm.2011.0127

30. Mannion C, Mansell D. Hindawipublishing corporation. Obstetrics and Gynecology International Volume, 2012, doi:10.1155/2012/562704. 